\title{
Isolated unilateral idiopathic transient hypoglossal nerve palsy
}

\author{
Syed Viqar Ahmed, Muhammad Saqub Akram
}

Department of Acute Medicine, Stepping Hill Hospital,

Stockport, UK

\section{Correspondence to}

Dr Syed Viqar Ahmed, syedviqarahmed@hotmail.com

Accepted 30 May 2014

\section{SUMMARY}

A 52-year-old Caucasian man presented with sudden onset of difficulty in moving his tongue to the left with preceding left-sided headache with no neck pain. Earlier, he had self-limiting chest infection without rashes or tonsillar enlargement. His medical and surgical history was unremarkable with no recent trauma. Oral examination revealed difficulty in protruding his tongue to the left with muscle bulk loss and fasciculation on the same side, suggesting left hypoglossal nerve palsy. Examination of the rest of the cranial nerves and nervous system was normal. The patient's oropharyngeal and laryngeal examination was unremarkable with no cervical lymphadenopathy. He had normal laboratory investigations and cerebrospinal fluid examination. Extensive imaging of the head, neck and chest failed to reveal any pathology. Further review by an otorhinologist and rheumatologist ruled out any other underlying pathology. He made a good recovery without treatment. English literature search revealed very few cases of idiopathic, transient, unilateral hypoglossal nerve palsy.

\section{BACKGROUND}

Usually, hypoglossal nerve palsy is seen with involvement of other cranial nerves in a varied group of illnesses, listed in the Differential diagnosis section. It is rarely involved in isolation and rarer to be affected without an obvious cause, hence analogous to Bell's palsy. ${ }^{1}$

We report a case of isolated, unilateral hypoglossal nerve palsy where extensive investigations failed to identify an apparent cause. Spontaneous recovery without any specific treatment indicated transient palsy. Extensive English literature search revealed limited number of similar cases that are briefly discussed in the Discussion section.

\section{CASE PRESENTATION}

A 52-year-old Caucasian man, life-long non-smoker, no tobacco chewing, was admitted via his general practitioner with sudden onset of difficulty in moving his tongue to the left and manipulating food in his mouth. He had a constant feeling of his tongue not being 'right'. There was no nasal regurgitation. This was preceded by a 3-day history of sudden onset of dull headache while driving. It was constant headache of moderate intensity and mostly affected the left side of the occipital region. Apart from one episode of vomiting the following day, he did not have any visual symptoms, ptosis, diplopia, facial weakness, dysarthria or swallowing difficulties. There was no neck pain, vertigo, limb weakness, sensory symptoms or gait problems while the speech was normal. A week before the episode, he knocked the front of his head on his cellar ceiling when he lost his footings but there was no fall, injury or loss of consciousness. It was not followed by any headaches. He had a recent history of upper respiratory tract viral infection but no symptom of rashes or tonsillar enlargement. His medical history included long-standing left-sided tinnitus and reduced hearing and spontaneous pneumothorax 30 years ago. There was no surgical history of note and no recent weight loss. His initial laboratory investigations showed normal blood count, normal routine biochemistry and blood glucose levels.

On examination, there was no cervical lymphadenopathy. His neurological examination was as follows: visual acuity was $6 / 9$ bilaterally with normal eye movements. There was no ptosis or miosis and the funduscopic examination was normal. He did not have any facial weakness, palatal movements were midline and voice was normal. His tongue examination revealed difficulty in protruding to the left with marked left-sided muscle bulk loss, tongue fasciculation and a loss of power and movement on the same side. His oropharyngeal examination showed dental caries, normal gag reflex and normal tonsillar fossae. The left-sided tongue base was more prominent than the right, in keeping with the change in muscle bulk on this side. There were no obvious masses or lesions and the glottis and subglottis were unremarkable. There were no shoulder girdle muscle wasting or winging of the scapula. Motor system examination showed no drift with tone, power and reflexes were equal and symmetrical in the upper and lower limbs. There was bilateral flexor planter response with normal gait and coordination (video 1).

\section{INVESTIGATIONS}

Laboratory investigations showed normal results for full blood count, routine biochemistry, C reactive protein and blood glucose levels. His chest $\mathrm{X}$-ray and brain CT scan were normal. His cerebrospinal fluid examination was normal for glucose, protein, cytology, viral PCR and culture. MRI of the brain with gadolinium showed no leptomeningeal enhancement, mass lesions or skull base pathology. There were incidental inflammatory changes in the maxillary sinuses. An otorhinologist performed direct examination of the nasopharynx and larynx to rule out any retropharyngeal pathology. Further imaging (MRI of the craniofacial with contrast/MRI of the neck) to follow the hypoglossal canal and hypoglossal nerve did not reveal any abnormality or identified any masses or lesions. 


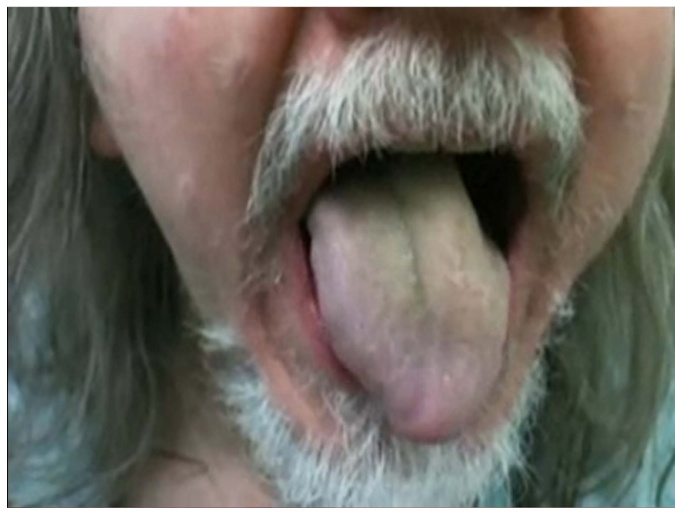

Video 1 Left sided hypoglossal nerve palsy.

In view of borderline positive rheumatoid factor (16 units), he was seen by a rheumatologist who did not think it was of any clinical significance. This was supported by normal results for autoantibodies, complement levels and inflammatory markers.

\section{DIFFERENTIAL DIAGNOSIS}

Causes of hypoglossal nerve palsy

- Primary

- Idiopathic type

- Secondary

- Metastatic disease at the base of skull

- Medical causes, for example, sarcoidosis, autoimmune disease and vasculitis

- Arnold-Chiari malformation

- Dural arteriovenous fistula of the transverse sinus

- Periostitis of hypoglossal canal

- Postretropharyngeal infection

- Surgical procedure near the neck

- Acute poliomyelitis

- Syringobulbia

- Thrombosis of median branches of vertebral artery

- Multiple sclerosis

- Carotid artery dissection/aneurysm

- Diabetes mellitus

- Lacunar infarct over the hypoglossal nerve nucleus

- Rare sequelae of central venous catheterisation

- Head and neck trauma, for example, sublaxation of odontoid process

- Fracture through the occipital condyle

- Glomus tumour

- Meningioma

- Persistent hypoglossal artery

\section{TREATMENT}

Our patient improved spontaneously without any specific treatment. In postinfectious hypoglossal nerve palsy, oral corticosteroids have been used with variable results. ${ }^{2}$

Oral steroids may hasten the recovery but there are no studies on the use of steroids in the idiopathic variety of cases.

\section{OUTCOME AND FOLLOW-UP}

Following discharge from the hospital, he has continued to improve. His tongue movements are now normal though some residual weakness and wasting of the left side of the tongue persists. He reports of some difficulty in getting food out of the left buccal cavity when he eats and slight lisp when he speaks.

\section{DISCUSSION}

The 12th cranial nerve is a motor nerve for the tongue muscles. It may be affected at the nucleus level in the medulla, its intracranial section along the skull base or extracranial section and across the hypoglossal canal. It is rarely involved in isolation and its paralysis is a diagnostic challenge; in most cases it is indicative of an underlying serious pathology and needs thorough investigations to look for a cause. Idiopathic variety is extremely rare and is a diagnosis of exclusion. A careful history and investigations may reveal causes ${ }^{3}$ related to malignancy, head and neck trauma, ischaemia, vaculitis, neuropathy or inflammatory lesions. The commonest causes ${ }^{4}$ are malignancy, trauma, stroke and bulbar palsy. Although very rare, it may be that an early manifestation of demyelinating disease and a repeat MRI of the brain every 5 years may be considered. ${ }^{3}$

Occasionally, the fetal communication between the carotid and vertebrobasilar arteries persists into adult life, which can be identified by MR angiography in the form of persistent hypoglossal artery. The enlarged hypoglossal artery in the narrow hypoglossal canal may impinge on the neighbouring hypoglossal nerve that could lead to intermittent hypoglossal nerve palsy. ${ }^{5}$ In our case, no MR angiography was performed but MRI with contrast showed no evidence of any abnormal enhancement within the visualised left hypoglossal canal.

In our case, extensive investigations failed to identify any cause for hypoglossal nerve palsy. The follow-up review showed spontaneous recovery. It is therefore fair to assume that it is a rare case of isolated, unilateral, idiopathic type of hypoglossal nerve palsy. A comprehensive literature search was carried out using several search engines: EMBASE, MEDLINE, Trip database, Case reports, PubMed, Cochrane Library, CINAHL, PsycINFO, AMED, BNI, Health Business Elite and HMIC. Without putting a date limit, we found only 13 case reports in the English literature with regard to the idiopathic type of hypoglossal nerve palsy. Most of these cases reported good recovery without any specific treatment. ${ }^{6}$

\section{Learning points}

- Idiopathic hypoglossal nerve palsy is a diagnosis of exclusion and all patients must be thoroughly investigated to look for a cause, particularly pathologies of the base of skull.

- It may be indicative of a demyelinating disease at a later stage and a repeat MRI of the brain in 5 years may be considered.

- Most cases of idiopathic aetiology have good prognosis and patients' assurance is an essential part of therapy.

- Speech and language therapy should be considered in all patients.

Acknowledgements The authors would like to thank Hamza Ahmed, who did the proofreading and helped with the video editing.

Competing interests None.

Patient consent Obtained.

Provenance and peer review Not commissioned; externally peer reviewed.

\section{REFERENCES}

1 Lee SS, Wang SJ, Fuh JL, et al. Transient unilateral hypoglossal nerve palsy: a case report. Clin Neurol Neurosurg 1994;96:148-51. 
2 Parano E, Giuffrida S, Restivo D, et al. Reversible palsy of the hypoglossal nerve complicating infectious mononucleosis in a young child. Neuropediatrics 1998;29:46-7.

3 Ho MW, Fardy MJ, Crean SJ. Persistent idiopathic unilateral isolated hypoglossal nerve palsy: a case report. Br Dent J 2004;196:205-7.

4 Keane JR. Twelfth-nerve palsy. Analysis of 100 cases. Arch Neurol 1996;53:561-6.
5 Meila D, Wetter A, Brassel F, et al. Intermittent hypoglossal nerve palsy caused by a calcified persistent hypoglossal artery: an uncommon neurovascular compression syndrome. J Neurol Sci 2012:323:248-9.

6 Combarros 0 , Alvarez de Arcaya A, Berciano J. Isolated unilateral hypoglossal nerve palsy: nine cases. J Neurol 1998;245:98-100.

Copyright 2014 BMJ Publishing Group. All rights reserved. For permission to reuse any of this content visit http://group.bmi.com/group/rights-licensing/permissions.

BMJ Case Report Fellows may re-use this article for personal use and teaching without any further permission.

Become a Fellow of BMJ Case Reports today and you can:

- Submit as many cases as you like

- Enjoy fast sympathetic peer review and rapid publication of accepted articles

- Access all the published articles

- Re-use any of the published material for personal use and teaching without further permission

For information on Institutional Fellowships contact consortiasales@bmjgroup.com

Visit casereports.bmj.com for more articles like this and to become a Fellow 